\title{
Extended anticoagulation in cancer-associated thrombosis
}

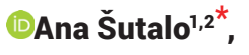 \\ (D)Ana Marija Slišković', \\ (D) Mislav Puljević', \\ (iD)Ante Bosnić', \\ (DLjiljana Banfić', \\ (D)Majda Vrkić \\ Kirhmajer ${ }^{1}$ \\ 'University of Zagreb School \\ of Medicine, University \\ Hospital Centre Zagreb, \\ Zagreb, Croatia \\ ${ }^{2}$ General Hospital "Dr Tomislav \\ Bardek", Koprivnica, Croatia
}

RECEIVED:

December 5, 2020

ACCEPTED:

December 18, 2020

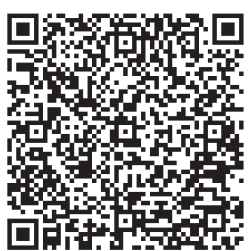

$\square$ Cardiologia Croatica 2021;16(1-2):72.
KEYWORDS: cancer associated thrombosis, venous thromboembolism recurrence, prolonged anticoagulation treatment.

CITATION: Cardiol Croat. 2021;16(1-2):72. | https://doi.org/10.15836/ccar2021.72

*ADDRESS FOR CORRESPONDENCE: Ana Šutalo, Opća bolnica “dr. Tomislav Bardek”, Željka Selingera 1, HR-48000 Koprivnica, Croatia. / Phone: +385-99-4023194 / E-mail: anasutalo1989@gmail.com

ORCID: Ana Šutalo, https://orcid.org/0000-0002-7644-6362 • Ana Marija Slišković, https://orcid.org/0000-0001-6622-7572 Mislav Puljević, https://orcid.org/0000-0003-1477-2581 • Ante Bosnić, https://orcid.org/0000-0003-4019-3874 Ljiljana Banfić, https://orcid.org/0000-0002-4538-8980 • Majda Vrkić Kirhmajer, https://orcid.org/0000-0002-1340-1917

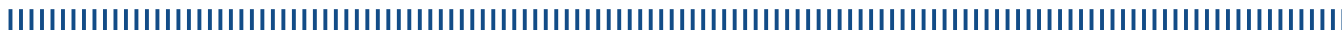

Introduction: Compared with the general population, cancer patients with venous thromboembolism (VTE) have higher rates of both VTE recurrence and bleeding. Low molecular weight heparins (LMWH) are the standard of care for the treatment of cancer-associated venous thromboembolism (CAT). Direct oral anticoagulants (DOACs) have recently emerged as a new therapeutic option, but optimal duration of therapy is still unclear. Decision for prolonged anticoagulation treatment is made individually as it depends on disease activity, current antineoplastic regime and patient risk-benefit profile ${ }^{1-3}$

Patients and Methods: A single center retrospective analysis of patients with CAT was conducted. The aim was to investigate type and duration of anticoagulation therapy. From our database of patients with VTE collected between 2016 and 2020, we included those with cancer associated deep venous thrombosis and/or pulmonary embolism.

Results: The cohort consisted of 44 patients (40\% women and 60\% male), aged 20 to 91 years. Therapeutic options at discharge were LMWH in $60 \%$ cases (enoxaparin and dalteparin equally represented), VKA in $25 \%$ and DOAC in $15 \%$. One patient was dismissed without anticoagulation because of an endstage gastric carcinoma which manifested as acute gastrointestinal bleeding. In follow-up period we observed that 20 patients (45\%) had extended anticoagulation beyond 6 months: 50\% LMWH, 30\% rivaroxaban, 20\% VKA. Among them, four patients initially treated with LMWH, were transited to rivaroxaban because of reduced tolerability of parenteral drug. One case of major bleeding occurred (hematuria) but there were no fatal or intracranial bleeding episodes in CAT patients on extended anticoagulant therapy in follow up period.

Conclusion: Treatment of VTE in patient with cancer remains a clinical challenge. Guidelines recommend at least 6 months of therapy for CAT and longer if the patient has active cancer or is receiving antineoplastic therapy. Extended anticoagulation may include LMWH or transition to an oral anticoagulant. Since carcinoma carries both thromboembolic and bleeding risk, the decision should be made on a case-by-case basis. From our experience, that assumes regular clinical reassessments.

LITERATURE IIIIIIIIIIIIIIIIIIIIIIIIIIIIIIIIIIIIIIIIIIIIIIIIIIIIIIIIIIIIIIIIIIIIIIIIIIIIIIIIIIIIIIIIIIIIIIIIIIIIIIII

1. Vedovati MC, Giustozzi M, Becattini C. Venous thromboembolism and cancer: Current and future role of direct-acting oral anticoagulants. Thromb Res. 2019 May;177:33-41. https://doi.org/10.1016/j.thromres.2019.02.031

2. Key NS, Khorana AA, Kuderer NM, Bohlke K, Lee AYY, Arcelus JI, et al. Venous Thromboembolism Prophylaxis and Treatment in Patients With Cancer: ASCO Clinical Practice Guideline Update. J Clin Oncol. 2020 Feb 10;38(5):496-520. https://doi.org/10.1200/JC0.19.01461

3. Ay C, Beyer-Westendorf J, Pabinger I. Treatment of cancer-associated venous thromboembolism in the age of direct oral anticoagulants. Ann Oncol. 2019 Jun 1;30(6):897-907. https://doi.org/10.1093/annonc/mdz111 